\title{
ОБОСНОВАНИЕ ЭКОНОМИЧЕСКОГО ПРЕИМУЩЕСТВА МОРСКОЙ ТРАНСПОРТИРОВКИ АРКТИЧЕСКОГО ПРИРОДНОГО ГАЗА В ВИДЕ СПГ
}

\author{
С.Ю.КОЗЬМЕНКО ${ }^{1}$, В.А. МАСЛОБОЕВ ${ }^{2}$, Д.А.МАТВИИШИН ${ }^{1}$ \\ ${ }^{1}$ Мурманский государственный технический университет, Мурманск, Россия \\ ${ }^{2}$ Федеральный исследовательский центр «Кольский научный центр РАН», Апатиты, Россия
}

\begin{abstract}
Российская Арктика является крупнейшим экспортером отечественного природного газа, что приносит федеральному бюджету весомую долю доходов. Подавляющие объемы добываемого арктического природного газа транспортируются по трубопроводам в единственном направлении - в страны Европы. Из-за ряда причин ЕС ведет планомерную работу по сокращению зависимости от российского природного газа, в том числе путем увеличения импорта сжиженного природного газа (СПГ). Это происходит на фоне процесса переориентации мировых рынков природного газа с трубопроводного газа на сжиженный. Очевидное решение увеличение производства СПГ в Российской Арктике с последующей транспортировкой морским путем. Учитывая удаленность арктических месторождений от основных рынков сбыта, требуется выполнение сравнительного анализа себестоимости транспортировки газа по трубопроводам и морским путем в виде СПГ.

Авторами разработана методика определения себестоимости трубопроводной и морской транспортировки газа в сопоставимых условиях. Выполнены расчеты себестоимости транспортировки газа при доставке в Германию, Италию, Турцию и Китай. В результате анализа выявлено, что морская доставка 1 тыс. м дешевле трубопроводной по всем рассмотренным маршрутам в среднем на 106,30 дол. (-40,2 \%). Расчеты подтверждают наличие экономического преимущества морской транспортировки арктического природного газа в виде СПГ на ключевые существующие и перспективные рынки сбыта природного газа. Этим обосновывается необходимость рациональной замены трубопроводного газа сжиженным на рынках стран Европы (особенно Южной, где конкурентоспособность СПГ выше) и увеличение экспорта сжиженного природного газа в страны АТР. Предлагаемые меры позволят сократить себестоимость морской транспортировки природного газа в виде СПГ, что значительно повысит конкурентоспособность арктического природного газа на мировом и региональных рынках природного газа.
\end{abstract}

Ключевые слова: Арктика; природный газ; СПГ; стоимость транспортировки; арктические СПГ-проекты

Как цитировать эту статью: Козьменко С.Ю. Обоснование экономического преимущества морской транспортировки арктического природного газа в виде СПГ / С.Ю.Козьменко, В.А.Маслобоев, Д.А.Матвиишин // Записки Горного института. 2018. Т. 233. С. 554-560. DOI: 10.31897/PMI.2018.5.554

Введение. Российская Арктика богата полезными ископаемыми, среди которых особенно выделяются углеводородные ресурсы. Запасы нефти, природного газа, газового конденсата и каменного угля во всей Арктике оценены в размере 646 млрд б.н.э. (баррелей нефтяного эквивалента), в том числе 233 млрд б.н.э. разведанных и ориентировочно 413 млрд б.н.э. неразведанных. Это порядка $1 / 5$ от общего объема мировых запасов углеводородных ресурсов, причем природный газ в структуре этих запасов занимает наибольшую часть и составляет 73,8 \% от общего объема. В пределах российского арктического пространства локализовано около 17 \% всей арктической нефти и 70 \% всего арктического природного газа [11, с. 61-63].

Нефтегазовые доходы федерального бюджета Российской Федерации составляют (2017) $39,58 \%$ от общего объема доходов [8, с. 269-271]. При этом в Российской Арктике добывается около $17 \%$ нефти и более 85 \% природного газа от общего объема отечественной добычи. Причем освоение ресурсов нефти и газа активно переносится в акваторию арктического континентального шельфа и становится важнейшей составляющей стратегии морской деятельности России в Арктике в аспекте развития рационального недропользования и освоения морских ресурсов арктического континентального шельфа [9, с. 62].

Основная доля арктического природного газа на сегодняшний день доставляется потребителям с использованием трубопроводного транспорта, причем в единственном, традиционном со времен газопровода «Союз» направлении - в страны Европы. Однако в целом на рынках стран EC рост спроса на природный газ практически отсутствует как в последние десятилетия, так и не ожидается в долгосрочной перспективе (потребление в 2001 г. - 475,5 млрд м ${ }^{3}$, в 2016 г. 480,7 млрд м ${ }^{3}$, в 2040 г. - 510 млрд м $\left.^{3}\right)$.

Более того, на этом фоне происходит снижение доли арктического природного газа в газовом импорте европейских стран, поскольку Европейский Союз, заявляя о необходимости обеспечения энергетической безопасности стран-членов, проводит политику диверсификации поставщиков природного газа, в том числе путем поиска альтернативы российскому природному газу, с целью 
устранить геополитический характер использования национальных трубопроводных газотранспортных систем. Результатом принимаемых ЕС мер стало сокращение доли российского природного газа в общем объеме импорта стран Европы с 41 до 35 \% за период с 2001 по 2016 гг.

В то же время, около 50 \% европейского потребления газа покрываются импортом, 4/5 объема которого обеспечивается «большой четверкой»- ПАО «Газпром» (Россия), Statoil ASA (Норвегия), Sonatrach (Алжир) и N.V.Nederlandse Gasunie (Нидерланды) [13, с. 96]. Таким образом, несмотря на сохранение значительной зависимости стран ЕС от импортного природного газа, происходит перераспределение объемов поставок между поставщиками не в пользу России. При этом сегодня главной альтернативой трубопроводному газу становится инновационный сжиженный природный газ (СПГ) [2, с. 73-82].

Общемировое потребление сжиженного природного газа растет примерно на $6 \%$ ежегодно, в то время как трубопроводного газа - только на 2,4 \% в год; доля СПГ в потреблении природного газа в энергетике уже составляет $10 \%$ [3, с. 49]. Доля СПГ в общемировом экспорте постоянно растет и составляет уже $32 \%$ - 346,6 млрд м $^{3}$ природного газа из общего объема в 1084,1 млрд м ${ }^{3}$ (данные 2016 г.). Тенденция замещения трубопроводного природного газа сжиженным отчетливо прослеживается в последние годы. Сохранение этой тенденции ожидается в долгосрочной перспективе (до 2040 г.) [5, с. 69-77].

Таким образом, экономическая привлекательность трубопроводного газа по сравнению с СПГ снижается. Это выражается и в утрате экономического значения так называемой гронингенской модели ценообразования [14, с. 31], которая предполагает реализацию природного газа исключительно в рамках долгосрочных контрактов. Соответственно, былое инновационное значение теряют как сам трубопроводный газ, так и порядок определения контрактной цены, которая рассчитывается по так называемой «роттердамской формуле» в соответствии с котировками Роттердамской биржи (FOB ARA Barges). Торговля СПГ, изначально начавшаяся также в рамках долгосрочных контрактов, сегодня значительно изменяется, поскольку растет объем спотовой торговли СПГ на специализированных газовых биржах - хабах. Это ведет к становлению СПГ в качестве самостоятельного глобального продукта [12, с. 57-67].

На этом фоне в Российской Арктике ПАО «НОВАТЭК» реализует крупные СПГ-проекты: «Ямал СПГ» и «Арктик СПГ-2». Следует особо подчеркнуть, что реализация крупных инфраструктурных проектов в нефтегазовой сфере окажет положительное влияние на социальноэкономическое развитие арктических регионов [например, 10, с. 275-279].

В рамках проекта «Ямал СПГ», ресурсной базой которого является Южно-Тамбейское месторождение, на западном берегу Обской губы построен п. Сабетта, рядом с которым размещен завод по сжижению природного газа. Введена в эксплуатацию первая очередь завода мощностью 5,5 млн т, отгрузки газа на газовозы арктического класса $\operatorname{Arc7}$ [1, с. 55] ведутся с конца 2017 г. После ввода в эксплуатацию второй, третьей и четвертой очередей в 2018-2020 гг. общая мощность проекта достигнет 17,5 млн т СПГ. Отгрузки СПГ ведутся в страны Европы и АТР, с апреля 2018 г. - в рамках долгосрочных контрактов.

Проект «Арктик СПГ-2», реализуемый на базе Салмановского (Утреннего) месторождения, предполагает строительство СПГ-завода общей мощностью 16,5-18 млн т с запуском линий в 2022-2025 гг. Главным отличием проекта от предыдущего станет концепция размещения линий СПГ-завода на плавучих железобетонных платформах гравитационного типа, для строительства которых в Кольском заливе создаются четыре искусственных острова [7].

Таким образом, с учетом реализации указанных проектов, к 2025 г. общий объем производства арктического СПГ достигнет 35,5 млн т (почти $14 \%$ от объема торговли СПГ в 2016 г.). В то же время, учитывая удаленность арктических месторождений от основных потребителей, реализация арктических СПГ-проектов требует обоснования экономического преимущества морской транспортировки газа в виде СПГ в сравнении с традиционной трубопроводной доставкой.

Методология исследования. Обоснование экономического преимущества морской транспортировки газа в виде СПГ заключается в выполнении сравнительного анализа себестоимости транспортировки 1 тыс. м ${ }^{3}$ природного газа от арктических месторождений крупнейшего газодобычного региона страны (Ямальская, Надым-Пурская и Пур-Тазовская нефтегазоносные области Западно-Сибирской нефтегазоносной провинции [6, с. 15-18]) до ключевых сегодняшних и потенциальных потребителей российского природного газа. 
Себестоимость транспортировки 1 тыс. м³ природного газа при его доставке по трубопроводам рассчитывается по формуле:

$$
\mathrm{CP}_{\text {pipeline }}=\frac{E_{\text {pipeline }}}{100} r
$$

где $\mathrm{CP}_{\text {pipeline }}$ - себестоимость транспортировки 1 тыс.м³ природного газа по трубопроводу, дол.; $E_{\text {pipeline }}$ - протяженность трубопроводов для выбранного маршрута, км; $r$ - средняя стоимость прокачки природного газа по трубопроводам для выбранного маршрута, дол. за 1 тыс. м ${ }^{3}$ на 100 км.

При расчете себестоимости доставки природного газа по трубопроводам конечным пунктом доставки принимается граница страны-потребителя газа.

Себестоимость транспортировки 1 тыс. м $^{3}$ природного газа при его доставке морским путем в виде СПГ рассчитывается по формуле

$$
\mathrm{CP} \operatorname{lng}=L+\frac{\left(\frac{E \ln g \cdot 2}{S / 24}+1\right) d f r}{C}+\frac{G T i t}{C} \cdot 2+T r+\mathrm{P},
$$

где CPlng - себестоимость транспортировки 1 тыс. м³ природного газа при его доставке морским путем в виде СПГ, дол.; $L$ - стоимость сжижения 1 тыс. м природного газа, дол.; Elng - протяженность морского маршрута, морские мили $(\mathrm{nm}) ; S$ - скорость движения газовоза, узлы; $d f r$ - суточная ставка фрахта газовоза, дол.; $C$ - вместимость газовоза по объему СПГ, тыс. м³; $G T$ - валовая вместимость газовоза; $i t$ - тариф ледокольной проводки судна за единицу валовой вместимости судна, дол.; $T r$ - стоимость перевалки 1 тыс. м ${ }^{3}$ СПГ с газовоза ледового класса на газовоз конвенционного типа (если применимо), дол.; Р - стоимость прохода газовоза через Суэцкий канал в расчете на 1 тыс. м $^{3}$ СПГ (если применимо), дол.

Дискуссия и результаты. При расчете себестоимости доставки природного газа морским путем в виде СПГ конечным пунктом доставки принимается порт отгрузки СПГ, в котором расположен регазификационный терминал (поставка на условиях CIF). В себестоимости доставки природного газа морским путем в виде СПГ учитывается круговой рейс судна (т.е. с учетом возврата в первоначальный порт на следующую погрузку), включая сутки, отведенные на погрузку или разгрузку СПГ.

В расчетах используются следующие коэффициенты для перевода единиц измерения: $1 \mathrm{~T}$ СПГ $=1,38$ тыс. м $^{3}$ природного газа в свободном виде; $1 \mathrm{~m}^{3}$ СПГ $=572,6 \mathrm{~m}^{3}$ природного газа в свободном виде; $1 \mathrm{MMBtu}=35,99$ тыс. м $^{3}$ природного газа в свободном виде.

Авторами разработаны формулы с учетом особенностей математического моделирования систем добычи и транспорта природного газа в Арктической зоне России [4, с. 705-716] для расчета себестоимости транспортировки природного газа при его доставке по трубопроводам и морским путем в виде СПГ. Рассчитаем такую себестоимость для выбранных маршрутов: в страны Северной Европы (на примере Германии), в страны Южной Европы (на примере Италии и Турции) и в страны Азиатско-Тихоокеанского региона (на примере Китая). Выбор государств обусловлен возможностью сравнения себестоимости доставки обоими видами транспорта при сопоставимости маршрутов.

В расчетах использованы следующие исходные данные. В зависимости от территории, по которой пролегает трубопровод, примеряются различные средние стоимости прокачка газа. Средняя стоимость прокачки газа по газопроводам ЕСГ России и по территории стран-транзитеров составляет 5,5 дол. за 1 тыс. м ${ }^{3}$ на 100 км; по территории Бельгии, Германии, Словакии и Австрии 2,5 дол. за 1 тыс. м³ на 100 км; по территории Китая - 2,0 дол. за 1 тыс. м на 100 км.

Себестоимость сжижения 1 MMBtu природного газа составляет 2,85 дол., 1 тыс. $\mathbf{m}^{3}-$ 102,57 дол. Стоимость регазификации составляет 15 дол. Для доставки СПГ в страны Северной Европы и напрямую в страны АТР по Северному морскому пути используются газовозы арктического класса Arc7. Для последующей доставки в страны Южной Европы и страны АТР по «южному» маршруту через Суэцкий канал используются газовозы конвенционного типа Conventional без ледового класса; перевалка СПГ с газовозов Arc7 на газовозы Conventional выполняется в порту Зебрюгге. Скорость движения газовоза Arc7 во льдах (Карское море в зимне-весенний 
период, остальные арктические моря в летне-осенний период в тяжелых ледовых условиях) составляет 10 узлов, а скорость движения газовозов обоих типов по чистой воде (в свободных от льда водах) - 18 узлов.

Вместимость газовоза Аrc7 по объему СПГ составляет 172,6 тыс. м³ СПГ (98 830,76 тыс. м³ природного газа в свободном виде), а газовоза Conventional - 145 тыс. м ${ }^{3}$ СПГ (83 027 тыс. $\left.{ }^{3}\right)$. Суточная ставка фрахта газовоза Arc7 составляет 110 тыс. дол., газовоза Conventional 33,5 тыс. дол. Стоимость перевалки 1 тыс. м³ природного газа в порту Зебрюгге составляет 4,6 дол.; стоимость прохода газовоза по Суэцкому каналу (в обе стороны) - 6,37 дол. за 1 тыс. м го природного газа или около 9 дол. за 1 т СПГ.

При движении газовоза Arc7 в Карском море в зимне-весенний период и в остальных арктических морях в летне-осенний период в тяжелых ледовых условиях ему необходима ледокольная проводка. Стоимость ледокольной проводки рассчитывается, исходя из валовой вместимости газовоза (128 806 ед.) и тарифа ледокольной проводки судна за единицу валовой вместимости: 5,42 дол. для Карского моря в зимне-весенний период, 4,38 дол. для остальных арктических морей в летне-осенний период.

Расчет себестоимости транспортировки газа по трубопроводам выполнен от месторождений Бованенковское НГК и Уренгойское НГК, а себестоимости транспортировки газа морским путем в виде СПГ - от месторождения Южно-Тамбейское ГК. Для сопоставления рассчитанной по маршрутам себестоимости транспортировки газа каждым из видов транспорта при расчете средних значений учтены дополнительные расходы на транспортировку природного газа между месторождениями: по маршруту «Южно-Тамбейское ГКМ - Бованенковское НГКМ» (общая протяженность 170 км) эти расходы составляют 9,35 дол., а по маршруту «Южно-Тамбейское ГКМ Уренгойское НГКМ» $\left(760\right.$ км) - 41,8 дол. Сравнение себестоимости трубопроводной $\left(\mathrm{CP}_{\text {pipeline }}\right)$ и морской (CPlng) транспортировки 1 тыс. ${ }^{3}$ природного газа с Южно-Тамбейского ГКМ (ЮТГМК) по основным маршрутам представлено в таблице.

Сравнение стоимости трубопроводной и морской транспортировки природного газа ( дол./тыс. м³)

\begin{tabular}{l|c|c|c|c}
\hline \multirow{2}{*}{\multicolumn{1}{c|}{ Маршрут транспортировки }} & \multicolumn{2}{|c|}{ Трубопроводная транспортировка } & \multicolumn{2}{|c}{ Морская транспортировка } \\
\cline { 2 - 5 } & $\begin{array}{c}\text { Протяженность, км } \\
\text { (средняя) }\end{array}$ & $\begin{array}{c}\mathrm{CP}_{\text {pipeline }} \\
\text { (средняя) }\end{array}$ & Протяженность, км & СРIng \\
\hline ЮТГКМ - Германия & 4270 & 235,84 & 4700 & 152,98 \\
ЮТГКМ - Италия & 5570 & 279,38 & 8840 & 152,06 \\
ЮТГКМ - Турция & 5720 & 293,95 & 10330 & 153,56 \\
ЮТГКМ - Китай, через Суэцкий канал & 7370 & $247,60^{*}$ & 24000 & 165,0 \\
ЮТГКМ - Китай, через Северный морской путь & 7370 & $247,60^{*}$ & 11600 & 151,0
\end{tabular}

${ }^{*}$ Стоимость прокачки 1 тыс. м³ природного газа на 100 км по трубопроводу «Сила Сибири» составляет порядка 6,3 дол., по китайским магистральным трубопроводам - 2 дол.

По газопроводам в Германию российский арктический газ может доставляться по трем основным маршрутам: «Бованенковское НГКМ - Северный поток/Северный поток-2 - Германия» (общая протяженность 4294 км); «Бованенковское НГКМ - Ямал - Европа - Германия» (4 160 км); «Уренгойское НГКМ - Ямал - Европа - Германия» (3 860 км). Себестоимость транспортировки 1 тыс. м ${ }^{3}$ газа по указанным маршрутам составляет 236,17; 228,80 и 212,30 дол. соответственно. С учетом дополнительных расходов на транспортировку газа с Южно-Тамбейского ГКМ средняя себестоимость трубопроводной доставки 1 тыс. м³ российского арктического газа в Германию составляет 235,84 дол.

По газопроводам в Италию российский арктический газ может доставляться по двум основным маршрутам: «Бованенковское НГКМ - Северный поток/Северный поток-2 - Италия» (общая протяженность 5579 км, в том числе по территории Германии, Словакии и Австрии 1285 км) и «Уренгойское НГКМ - Дружба - Италия» (5 254 км, в том числе по территории Словакии и Австрии 803 км). Себестоимость транспортировки 1 тыс. м³ газа по указанным маршрутам составляет 268,30 и 264,88 дол. соответственно. С учетом дополнительных расходов на транспортировку газа с Южно-Тамбейского ГКМ средняя себестоимость трубопроводной доставки 1 тыс. $\mathrm{M}^{3}$ российского арктического газа в Италию составляет 279,38 дол. 
По газопроводам в Турцию российский арктический газ может доставляться по двум основным маршрутам: «Уренгойское НГКМ - Голубой поток - Турция» (общая протяженность 4709 км) и «Уренгойское НГКМ - Турецкий поток - Турция» (5 220 км). Себестоимость транспортировки 1 тыс. м ${ }^{3}$ газа по указанным маршрутам составляет 259,00 и 287,10 дол. соответственно. С учетом дополнительных расходов на транспортировку газа с Южно-Тамбейского ГКМ средняя себестоимость трубопроводной доставки 1 тыс. м ${ }^{3}$ российского арктического газа в Турцию составляет 293,95 дол.

По газопроводам в Китай российский арктический газ может доставляться по маршруту «Уренгойское НГКМ - Сила Сибири-2 - Китай» (общая протяженность 2700 км). Себестоимость транспортировки 1 тыс. м ${ }^{3}$ газа по указанному маршруту составляет 169,40 дол. Однако следует отметить, что основные потребители природного газа в Китае расположены в индустриально развитых районах страны - преимущественно на юго-востоке. Соответственно, себестоимость транспортировки природного газа в Китай представляется более корректном рассчитывать с учетом доставки не до границы страны, а до основных потребителей. Себестоимость дальнейшей транспортировки 1 тыс. м ${ }^{3}$ газа с северо-запада Китая на юго-восток составляет от 65,60 (Пекин, 3280 км по территории Китая) до 90,80 дол. (Гуанчжоу, 4540 км). Тогда с учетом дополнительных расходов на транспортировку газа с Южно-Тамбейского ГКМ средняя себестоимость трубопроводной доставки 1 тыс. м ${ }^{3}$ российского арктического газа в Китай составляет 247,60 дол.

Таким образом, средняя себестоимость транспортировки 1 тыс. м ${ }^{3}$ природного газа при его доставке по трубопроводам по всем рассмотренным маршрутам составляет 264,19 дол.

Рассмотрим стоимость морской доставки российского арктического газа в виде СПГ в Германию по двум маршрутам: «Южно-Тамбейское ГКМ (п. Сабетта) - Зебрюгге - Бельгийская ГТС Германия» (в Зебрюгге расположены как перегрузочный терминал для проекта «Ямал СПГ», так и регазификационный терминал Zeebrugge); «Южно-Тамбейское ГКМ (п. Сабетта) - Брунсбюттель / Штаде (Германия)» (в одном из этих портов Германия планирует строительство собственного регазификационного терминала). Общая протяженность морского пути от п. Сабетта до Зебрюгге составляет $2537,80 \mathrm{~nm}$, включая 485,96 nm в акватории Карского моря и $2051,84 \mathrm{~nm}$ в свободных от льда водах. После регазификации природный газ доставляется до Германии по Бельгийской ГТС (общей протяженностью 230 км). Себестоимость транспортировки 1 тыс. м ${ }^{3}$ по этому маршруту составляет в зимне-весенний период 153,64 дол., в летне-осенний - 139,51 дол. Общая протяженность морского пути от п. Сабетта до Брунсбюттель / Штаде составляет $2429,81 \mathrm{~nm}$, включая $1943,85 \mathrm{~nm}$ в свободных от льда водах. Себестоимость транспортировки 1 тыс. м $^{3}$ по этому маршруту составляет в зимне-весенний период 132,34 , в летне-осенний 118,21 дол. С учетом дополнительных расходов на транспортировку газа с Бованенковского НГКМ и Уренгойского НГКМ средняя себестоимость морской транспортировки 1 тыс. м ${ }^{3}$ российского арктического газа в виде СПГ в Германию составляет 152,98 дол.

Рассмотрим стоимость морской доставки российского арктического газа в виде СПГ в Италию по маршруту «Южно-Тамбейское ГКМ (п. Сабетта) - Зебрюгге - Ливорно (Италия)» (в Ливорно расположен регазификационный терминал LNG Toscana). Общая протяженность морского пути от п. Сабетта до Зебрюгге и, соответственно, себестоимость доставки газа по этому маршруту рассчитана ранее. В Зебрюгге выполняется перевалка СПГ на газовоз Conventional. Общая протяженность морского пути от п. Зебрюгге до Ливорно составляет $2235,42 \mathrm{~nm}$. Себестоимость транспортировки 1 тыс. м 3 по всему маршруту от п. Сабетта до Ливорно составляет в зимневесенний период 142,07 дол., в летне-осенний - 127,94 дол. С учетом дополнительных расходов на транспортировку газа с Бованенковского НГКМ и Уренгойского НГКМ средняя себестоимость морской транспортировки 1 тыс. м $^{3}$ российского арктического газа в виде СПГ в Италию составляет 152,06 дол.

Рассмотрим стоимость морской доставки российского арктического газа в виде СПГ в Турцию по маршруту «Южно-Тамбейское ГКМ (п. Сабетта) - Зебрюгге - Алиага (Турция)» (в Алиага расположены регазификационные терминалы Aliaga LNG и Etki LNG). Общая протяженность морского пути от Сабетта до Зебрюгге и, соответственно, себестоимость доставки газа по этому маршруту рассчитана ранее. В Зебрюгге выполняется перевалка СПГ на газовоз Conventional. Общая протяженность морского пути от Зебрюгге до Алиага составляет 3 039,96 nm. Себестоимость транспортировки 1 тыс. м ${ }^{3}$ по всему маршруту от п. Сабетта до Алига составляет в зимне- 
весенний период 143,57, в летне-осенний - 129,45 дол. С учетом дополнительных расходов на транспортировку газа с Бованенковского НГКМ и Уренгойского НГКМ средняя себестоимость морской транспортировки 1 тыс. м $^{3}$ российского арктического газа в виде СПГ в Турцию составляет 153,56 дол.

Рассмотрим стоимость морской доставки российского арктического газа в виде СПГ в Китай по следующим маршрутам: «Южно-Тамбейское ГКМ (п. Сабетта) - Зебрюгге - Цаофэйдянь / Тяньцзинь (Китай)» (в указанных портах, располагающихся вблизи г. Пекин, находятся регазификационные терминалы Hebei Tangshan Caofeidian LNG и Tianjin соответственно); «ЮжноТамбейское ГКМ (п. Сабетта) - Зебрюгге - Яншань / Жудун (Китай)» (в указанных портах, располагающихся вблизи г. Шанхай, находятся регазификационные терминалы Shanghai Yangshan и Jiangsu Rudong LNG соответственно); «Южно-Тамбейское ГКМ (п. Сабетта) - Зебрюгге Шэньчжэнь / Дунгуань / Чжухай (Китай)» (в указанных портах, располагающихся вблизи г. Гуанчжоу, находятся регазификационные терминалы Guangdong Dapeng LNG I, Guangzhou Dongguan LNG и Guangdong Zhuhai LNG соответственно); «Южно-Тамбейское ГКМ (п. Сабетта) - Северный морской путь - Цаофэйдянь / Тяньцзинь (Китай)»; «Южно-Тамбейское ГКМ (п. Сабетта) - Северный морской путь - Яншань / Жудун (Китай)»; «Южно-Тамбейское ГКМ (п. Сабетта) - Северный морской путь - Шэньчжэнь / Дунгуань / Чжухай (Китай)».

Общая протяженность морского пути от п. Сабетта до Зебрюгге и, соответственно, себестоимость доставки газа по этому маршруту рассчитана ранее. В Зебрюгге выполняется перевалка СПГ на газовоз Conventional. Общая протяженность морского пути от Зебрюгге через Суэцкий канал составляет до китайских портов: Цаофэйдянь / Тяньцзинь - 11 339,09 nm, Яншань / Жудун 10 745,14 nm, Шэньчжэнь / Дунгуань / Чжухай - 9 989,20 nm. Себестоимость транспортировки 1 тыс. м ${ }^{3}$ по всему маршруту от п. Сабетта до указанных портов составляет 166,$25 ; 165,14$ и 163,73 дол. соответственно.

Общая протяженность морского пути от п. Сабетта по Северному морскому пути до Берингова пролива составляет $2370,41 \mathrm{~nm}$. Протяженность дальнейшего пути до китайских портов: Цаофэйдянь / Тяньцзинь - 3 785,10 nm, Яншань / Жудун - 3 542,12 nm, Шэньчжэнь / Дунгуань / Чжухай $-4287,26 \mathrm{~nm}$. Себестоимость транспортировки 1 тыс. м ${ }^{3}$ по всему маршруту от п. Сабетта до указанных портов составляет 145,17; 143,92 и 147,76 дол. соответственно. В случае тяжелых ледовых условий, с учетом проводки ледоколом, себестоимость транспортировки 1 тыс. м по указанным маршрутам составляет 156,59; 155,34 и 159,18 дол. соответственно.

С учетом дополнительных расходов на транспортировку газа с Бованенковского НГКМ и Уренгойского НГКМ средняя себестоимость морской транспортировки 1 тыс. м ${ }^{3}$ российского арктического газа в виде СПГ в Китай составляет 172,95 дол.

Таким образом, средняя себестоимость транспортировки 1 тыс. м ${ }^{3}$ природного газа при его доставке морским путем в виде СПГ по всем рассмотренным маршрутам составляет 157,89 дол.

Заключение. На основании изложенных расчетов выполним сравнительный анализ себестоимости трубопроводной и морской (в виде СПГ) транспортировки российского арктического природного газа по приведенным маршрутам. Морская доставка 1 тыс. м ${ }^{3}$ дешевле трубопроводной при доставке: в Германию - на 82,86 дол. (-35,1\%); в Италию - на 127,32 дол. (-45,6 \%); в Турцию - на 140,39 дол. (-47,8 \%); в Китай - на 74,65 дол. (-30,1\%). По всем рассмотренным маршрутам морская доставка 1 тыс. м ${ }^{3}$ российского арктического газа в виде СПГ дешевле трубопроводной в среднем на 106,30 дол. (-40,2 \%).

Выполненные авторами расчеты подтверждают экономическое преимущество морской транспортировки арктического природного газа в виде СПГ на ключевые существующие и перспективные рынки сбыта природного газа. Этим обосновывается необходимость рациональной замены трубопроводного газа сжиженным на рынках стран Европы (особенно Южной, где конкурентоспособность СПГ выше) и увеличение экспорта сжиженного природного газа в страны АТР. Учитывая актуальные тенденции развития мирового и региональных рынков природного газа, это позволит России сохранить и увеличить собственную долю в мировом импорте природного газа, выйти на новые рынки сбыта и диверсифицировать направления транспортировки природного газа.

Однако, для становления Российской Федерации конкурентоспособным экспортером природного газа в виде СПГ, требуется: 
Обоснование экономического преимущества морской транспортировки..

- продолжить реализацию запущенных и приступить к реализации новых проектов по производству и транспортировке природного газа в сжиженном виде;

- увеличить инвестиции в разработку собственных технологий сжижения газа, которые позволят сократить себестоимость данного этапа транспортировки СПГ;

- проработать вопрос об уровне требуемого ледового усиления для газовозов, исходя из опыта эксплуатации газовозов Arc7 в рамках проекта «Ямал СПГ», что при снижении ледового класса судов позволит уменьшить ставку фрахта газовозов;

- локализовать на российских судоверфях строительство газовозов для транспортировки СПГ;

- сохранить и увеличить государственную поддержку компаний, выполняющих разработку новых технологий в сфере производства и транспортировки СПГ, а также непосредственно его производство и транспортировку.

Указанные меры позволят сократить себестоимость морской транспортировки природного газа в виде СПГ, что значительно повысит конкурентоспособность арктического природного газа на мировом и региональных рынках природного газа.

Благодарность. Исследование выполнено в соответствии с базовой частью государственного задания высшим учебным заведениям Минобрнауки России в части инициативных научных проектов по теме НИР «Раџиональная организация экономического освоения и морской транспортировки энергетических ресурсов в Российской Арктике», № 13.12713.2017/8.9.

\section{ЛИТЕРАТУРА}

1. Агарков С.A. Влияние модернизации морской газотранспортной системы на развитие арктического региона / С.А.Агарков, Д.А.Матвиишин // Север и рынок: формирование экономического порядка. 2017. Т. 2. № 53. С. 50-57.

2. Агарков С.А. Экономические региональные особенности морской транспортировки сжиженного природного газа / С.А.Агарков, Г.П.Евдокимов, С.Ю.Козьменко // Геополитика и безопасность. 2015. № 2 (30). С. 73-82.

3. Андреев П.С. Преимущества и перспективы расширения экспорта сжиженного природного газа из России в страны АТР // Азиатско-Тихоокеанский регион: экономика, политика, право. 2015. № 2 (35). С. 47-55.

4. Бондарев Э.А. Особенности математического моделирования систем добычи и транспорта природного газа в Арктической зоне России / Э.А.Бондарев, И.И.Рожин, К.К.Аргунов // Записки Горного института. 2017. Т. 228. С. $705-716$. DOI: 10.25525/PMI.2017.6.705.

5. Кравченко М.П. Геополитика природного газа // Вестник Московского государственного лингвистического университета. Серия: общественные науки. 2015. № 2 (713). С. 69-77.

6. Кравченко М.Н. Перспективы нефтегазоносности глубокопогруженных отложений осадочного чехла северных районов Западно-Сибирской нефтегазоносной провинции // Геология нефти и газа. 2012. № 6. С. 13-21.

7. О заключении договоров о создании 4 искусственных земельных участков в Кольском заливе (среднее колено) Баренцева моря: Распоряжение Правительства РФ от 15.06.2017 № 1245-р // Собрание законодательства РФ. № 25. Ст. 3739. 19.06.2017.

8. Остапенко Н.А. Нефтегазовые доходы в федеральном бюджете Российской Федерации // Аллея науки. 2017. № 15. T. 2. C. $269-271$

9. Стратегия морской деятельности и экономики природопользования в Российской Арктике / С.Ю.Козьменко, А.Н.Савельев, В.С.Селин, А.А.Щеголькова // Морской сборник. 2012. Т. 1988. № 11. С.58-63.

10. Череповицын A.E. Экономическое развитие региона в ходе реализации морских нефтегазовых проектов (на примере освоения месторождений проектов «Сахалин-1» и «Сахалин-2» /А.Е.Череповицын, Н.В.Смирнова // Записки Горного института. 2013. Т. 205. С. 275-279

11. Швец Н.Н. Нефтегазовые ресурсы Арктики: правовой статус, оценка запасов и экономическая целесообразность их разработки / Н.Н.Швец, П.В.Береснева // Вестник МГИМО-Университета. 2014. № 4 (37). С. $60-67$.

12. Щеголькова А.А. Модернизация системы транспортировки арктического природного газа в стратегической перспективе / А.А.Щеголькова, Л.Е.Евграфова // Север и рынок: формирование экономического порядка. 2017. Т. 2. № 53. С. 57-67.

13. Щеголькова А.А. Пространственная организация транспортировки энергетических ресурсов: экономика и геополитика // Геополитика и безопасность. 2015. № 2 (30). С. 95-99.

14. Konoplyanik A.A. Evolution of Gas Pricing in Continental Europe: Modernization of Indexation Formulas Versus Gas to Gas Competition. Dundee: University of Dundee. 2010. 31 p.

Aвторы: С.Ю.Козьменко, д-р экон. наук, профессор, fregat22@таіl.rи (Мурманский государственныий технический университет, Мурманск, Россия). В.А.Маслобоев, д-р техн. наук, профессор, masloboev@ksc.ru (Федеральный исследовательский иентр «Кольский научный иентр РАН», Апатиты, Россия). Д.А.Матвиишин, младиий научный сотрудник, ьеstumik@rambler.ru (Мурманский государственный технический университет, Мурманск, Россия).

Статья поступила в редакиию 15.05.2018.

Статья принята к публикации 10.07.2018. 